\title{
A viagem continua: as memórias reescritas de Vasco da Gama
}

The journey goes on: the rewritten memories of Vasco da Gama

Daniel Vecchio

Universidade Estadual de Campinas, Campinas, SP, Brasil

Gerson Luiz Roani

Universidade Federal de Viçosa, Viçosa, MG, Brasil

Resumo: Vasco da Gama não é uma figura histórica sempre colocada da forma através da qual muitos cronistas narraram sua empresa marítima, registrando somente o protagonismo dos grandes vultos do episódio considerado oficial. Por isso, buscamos nesse trabalho sintetizar um percurso pontuado pelas manifestações históricas e literárias que produzem representações distintas de seu caráter e de suas viagens. Considerar Vasco da Gama enquanto tema, nos permitirá olhar de forma mais atenta e substanciada os textos subsequentes que dialogam com os antigos registros celebrativos desse importante personagem da história de Portugal.

Palavras-chave: Vasco da Gama. Descobrimentos. Imaginário. Memória.

Abstract: Along with the legendary and heroic figure of Vasco da Gama from traditional narratives and chronicles of Portuguese history, there are many other biographical and fictional versions of his "story". In this article, we present some of these versions, which reflect particular historical tendencies in history throughout many centuries, and reveal a certain imaginary instability and political bias in the representation of heroes. By considering Vasco da Gama a thematic issue we will be able to read subsequent writing about his "life" as part of an imaginary and political development of historical methods. Keywords: Vasco da Gama. Discoveries. Imaginary. Memory. 
Sabemos que a memória é uma reconstrução continuamente atualizada do passado, cujos enquadramentos são compartilhados por campos diversos, como a história e a literatura. Sob diversificadas formas individuais e coletivas da memória, esses dois saberes refletem dinâmicas culturais, narrativas e simbólicas de representação. Os estudos sobre a memória entendida como fenômeno coletivo e social são recentes, reDaniel montam aos trabalhos pioneiros de Maurice Halbwachs (1877-1945). Em Vecchio

Gerson suas teses, é impossível dissociar os efeitos ligados às representações da memória individual daqueles relacionados às representações da memória coletiva, por esse sociólogo francês considerar a primeira um mero fragmento da segunda, conferindo a essa última instância mnemônica maior poder de manifestação (HALBWACHS, 2006).

No entanto, em sua acepção corrente, a expressão "memória coletiva" é, sobretudo, "uma representação, uma forma de metamemória [...]." (CANDAU, 2012, p. 25). Nessa perspectiva, a faculdade da memória realmente manifestada é a memória individual, pois a metáfora memória coletiva aplicada a um grupo só seria totalmente pertinente se todos os seus membros fossem de fato capazes de compartilhar integralmente um número determinado de representações relativas ao passado.

Por isso, não é temerário afirmar que um dos grandes problemas da memória, que é também próprio da história e da literatura, consiste no fato de sua representação estar sujeita a vários tipos de apropriação do passado pelos diversos indivíduos e grupos sociais, feita através de celebrações, produções e evocações diversas que não escapam a esse processo de manipulação. Na apreensão das linhas de força da memória, identificamos como um traço forte e persistente de seu processo de representação a existência de um fundo mítico que foi sendo reelaborado ao sabor celebrativo das épocas e dos regimes políticos.

As celebrações eram o pretexto para reatualizar mitos, e "os centenários dos grandes homens deveriam ser uma forma de substituir os tradicionais objetos de veneração das religiões por outros mais adequados aos grupos sociais modernos" (JOÃO, 2002, p. 506-507). No caso português, assim como em vários outros países europeus, destacou-se o ciclo comemorativo da expansão ultramarina, que promoveu uma larga produção de estudos, obras de arte, exposições e mostras culturais sobre esse período. Um dos temas mais recorrentes é a viagem de Vasco da Gama, monumentalizado como o herói do descobrimento do 
caminho marítimo para a Índia, cujas manifestações históricas e ficcionais serão, neste texto, seletamente abordadas.

No entanto, Vasco da Gama está longe de ser uma definida figura histórica, mas uma fonte plural de interpretações, pois nem sempre tal figura foi colocada de acordo com a forma através da qual muitos cronistas narraram suas empresas, sob o protagonismo dos grandes vultos da história oficial. Assim, julgamos conveniente sintetizar um percurso pontuado pelas manifestações históricas e literárias que representaram as viagens gâmicas. Aqui, tal exercício analítico valoriza, sobretudo, uma prática que não reduz o tema a um fenômeno marcadamente isolado, isento de qualquer herança ou tradição, mas como um processo que dialoga com a cultura portuguesa.

Para começar tal contextualização, vale destacar as palavras de A viagem continua Vitorino Magalhães Godinho (1918-2011) ao dizer que "a história dos descobrimentos e da expansão crescera ao serviço de reivindicações nacionais e na obsessão das prioridades no descobrir e ocupar" (GODINHO, 2008, p. 25). Em seu clássico A expansão quatrocentista portuguesa, obra censurada pela comissão organizadora das Comemorações Henriquinas em 1960, torna-se muito evidente a sua ideia de que só uma sociologia histórica das comemorações dos descobrimentos portugueses é capaz de nos elucidar o que representou de fato tal evento para a coletividade lusitana. É nesse sentido que abordaremos algumas construções desse episódio.

Para cercarmos as representações do Gama na história e na literatura, seria produtivo termos em mãos relatos do próprio Capitão para elucidarmos alguns traços da sua memória e, por consequência, da sua identidade. Porém, não temos atualmente conhecimento de textos escritos por ele. Talvez nada escrevera, até suas funções de Almirante a isso o terem obrigado, tais como algumas poucas cartas de requerimento ao rei e ordens destinadas à sua tripulação. Não nos chegou qualquer relato de sua autoria sobre as três viagens que realizou para a Índia nos anos de 1497, 1502 e 1524.

A afirmação de que o Gama teria escrito uma relação de sua primeira viagem tornou-se muito vulgar. Pode ser provável, também, que o manuscrito descoberto no Arquivo Municipal do Porto em 1834, que marca o registro mais antigo sobre as viagens de Vasco da Gama, fosse anteriormente conhecido e noticiado como escrito pelo navegador. O professor de Matemática, Diogo Kopke (1808-1844), e o professor de 
Botânica, Antônio da Costa Paiva (1806-1879), ambos da Academia Politécnica do Porto, descobriram, na gaveta número 804 dos empoeirados arquivos da Biblioteca Municipal dessa cidade, esse manuscrito que imediatamente perceberam ter sido redigido no século XV. Sabe-se que ele fora trazido, poucos anos antes, da biblioteca do antigo Mosteiro de Santa Cruz de Coimbra e nada mais.

Daniel Depois de estudarem por quatro anos a fio tal manuscrito, Diogo Vecchio

Gerson Luiz Roani Kopke e Costa Paiva, convencidos de sua autenticidade, decidiram publicá-lo às próprias custas, em fevereiro de 1838, com o título Roteiro da viagem que em descobrimento da Índia pelo Cabo da Boa Esperança fez Dom Vasco da Gama em 1497. Os investigadores portuenses, no entanto, atribuíram sua autoria não ao Capitão, mas ao marinheiro chamado Álvaro Velho. A identificação de seu autor partiu da hipótese de que, na crônica de Fernão Lopes de Castanheda (1500-1559), História do descobrimento e conquista da Índia pelos portugueses (1551-1552), o autor do relato fora nomeado como parte da escolta com a qual Vasco da Gama desembarcara para realizar a primeira embaixada ao samorim de Calicute. ${ }^{1}$

Supuseram tais investigadores que o autor do relato só poderia ser um dos 13 marinheiros destacados por esse cronista. Kopke e Paiva utilizaram-se de argumentos sólidos e engenhosos para eliminá-los um a um, restando, por fim, apenas Álvaro Velho. Trata-se do principal documento para o estudo da viagem de Vasco da Gama, escrito por uma testemunha presencial dos fatos que relata. Nessa relação, segundo as palavras de João Rocha Pinto, “os acontecimentos de monta comandam a escrita e não o tempo, como aconteceria se fosse de fato um diário de bordo" (PINTO, 1989, p. 121).

Esta é, aliás, a mais importante característica narrativa que deve ser destacada de uma relação de viagem, ou seja, uma narração que se deixa tomar por completo pela descrição do espaço empírico, cobrindo os contatos com terras, ilhas e pontos costeiros que surgem ao longo da viagem, como vemos no excerto: "Estando nesta angra de Sam Bras

1 Não existem informações acerca do nascimento ou morte de Álvaro Velho (1450?-1500?), e não sabemos das suas funções a bordo. Encontramos, no entanto, duas únicas obras que lhe fazem menção: o Manuscrito Valentim Fernandes (Academia Portuguesa de História, 1940), no qual é mencionado o nome Álvaro Velho do Barreiro como a fonte viva para que o cronista realizasse a sua descrição das costas da Guiné; e, como visto, na História do descobrimento e conquistas da Índia pelos portugueses (1553), de Fernão Lopes de Castanheda, participando da primeira embaixada de Gama ao Samorim, rei de Calicute. Nesta pesquisa, utilizamos a seguinte versão do documento: $O$ descobrimento das Índias: o diário da primeira viagem de Vasco da Gama. Trad. de Ângela Ritzel. Rio de Janeiro: Objetiva, 1998. 
tomando agoahuũa quarta feira posemos huũa cruz e huũ padram em a dita amgra de Sam Bras, a qual cruz fezemos de huũamezena e era mujto alta" (VELHO, 1998, p. 166).

Com essa estratégia narrativa, não encontramos um perfil ou retrato efetivo de Vasco da Gama, diríamos que não estava na natureza do gênero fazê-lo. O que apenas podemos apontar de saliente no perfil de Vasco da Gama da relação de Álvaro Velho é o seu retrato moral de Capitão-mor na qualidade dos seus atos de grande prudência e virtude, demonstrando rígido cumprimento e obediência do regimento para uma segura navegação e da execução de embaixadas que lhe ordenou fazer o rei: "E o capitam lhe dise como elle era embaixador de huũ Rey de A viagem Portugall o quall era senhor de mujta terra e era mujtorrico de todas as cousasmajs que nenhũ Rey daquellas partes [...]" (VELHO, 1998, p. 178).

Devemos perceber que essa estratégia de escrita da relação em questão corrobora para que as emoções individuais de tal empresa não fossem alvo de registros. Parece que, de modo geral, a viagem nem sequer sensibilizou seu narrador. Poderíamos concluir que o seu dispêndio de meses em alto-mar foi relativamente suportável e sem grandes problemas. Porém, nem por isso "a arquitetura semântica de Álvaro Velho se apresenta como construção neutra, operatória e racionalizante, mas ainda sim, como mensagem registadora da intuição [...]" (BARRETO, 1983, p. 129).

Descrever somente os espaços percorridos foi uma estratégia que não evitou que o texto de Álvaro Velho falhasse na pretensão exclusiva à veracidade da realidade representada. Podemos perceber na leitura da relação uma pequena parte das emoções do narrador que embaralhou a consistência verídica dessas descrições, fazendo confundir imaginariamente os espaços e os objetos observados.

Atenta-se o leitor da relação que há momentos muito recorrentes em que o narrador afirma ver "xhristãos", afirmação que aparece na descrição de Moçambique à costa do Malabar. Uma das principais cenas narradas focaliza justamente o momento no qual desembarca o Capitão Vasco da Gama com sua embaixada na atual cidade indiana de Kozhikode e em que o narrador começa a adquirir provas sucessivas de que aquela terra pertence aos cristãos, observando suas igrejas, suas imagens de santos e de outros seres divinos: 
Daniel

Vecchio

Gerson

Luiz Roani

Aquy nos levaram a hua grande Igreja em a quall estavam estas cousas seguintes. Primeiramente ho corpo da Igreja He da granduraduu mosteiro toda lavrada de quantaria, telhada de ladrilho, e tinha a porta principallhu padram daramedaltura de humasto e em cima deste padram esta hua ave que parece gallo, e outro padram daltura de huuomem e mujto groso. E em meo do corpo da Igreja esta huucorucheo todo de quanto, e tinha hua porta quanto huu home cabia, e hua escada de pedra prquesobiam há esta porta, e dentro estava huuaymagem pequena a quallelles diziam que era nosa Senhora [...]. (VELHO, 1998, p. 176).

Álvaro Velho, julgando estarem os portugueses rodeados de cristãos convertidos por São Tomé, tem a ilusão, ao entrar em um templo hindu, de se encontrar em uma igreja. Sabemos que os portugueses daquela época ainda não conheciam os hindus, acabando por confundi-los com cristãos. “Tudo indica Gama ter zarpado de Portugal partindo do princípio de que a Índia era sobretudo habitada por cristãos, com uma minoria muçulmana [...]." (DISNEY, 2010, p. 297-298).

Podemos concluir, com isso, que o olhar não representa uma ferramenta de mera neutralidade empírica, pois, denominando os hindus de cristãos, a relação de Álvaro Velho testemunha a impossibilidade do português de observar os espaços aceitando as diferenças étnicas. Essa impossibilidade ocorre devido ao seu ponto de vista imaginário e ao seu aspecto cultural limitado. ${ }^{2}$

A primeira historiografia acerca das viagens dos descobrimentos portugueses, compostas por cronistas e historiadores, como Jerônimo Osório, Damião de Góis, Fernão Lopes de Castanheda, Gaspar Correia e João de Barros, surge como um discurso ressonante dos muitos imaginários e, principalmente, da virtuosidade dos navegadores representados nas relações que lhes serviram de base documental. Podemos perceber o realce desse último caráter em um pequeno trecho do cronista Jerônimo Osório (1506-1580): “[...] D. Manuel encomendou juntamente com o patrimônio da Realeza esta navegação a descobrir, e o Lusitano império a propagar." (OSÓRIO, 1804, p. 48).

"Descobrir" e "propagar" remetem a uma união de duas práticas que sustentarão a ideia de expansão criada pelos portugueses nos

2 É frequente a referência das fontes às cristandades orientais na figura do apóstolo São Tomé, que estaria na origem da conversão dessas comunidades: "Segundo a tradição lendária, baseada no apógrafo do século III Actos de Tomé, a Îndia ter-lhe-ia sido atribuída.” (FONSECA, 1997, p. 253). 
séculos XV e XVI. Os descobrimentos e a expansão ocupavam, já nessa época, um lugar muito importante no quadro evolutivo que estabeleciam para o desenvolvimento da humanidade, inserindo-o no movimento cultural e científico do Renascimento. Com essa base documental e essa historiografia incipiente sobre os navegadores e suas viagens de descobrimento, concluímos que "a forma como uma sociedade imagina o seu passado é um produto de complexas estruturas antropológicas de todo um imaginário sociocultural e um interessante objeto de falsa consciência [...]" (BARRETO, 1983, p. 9-10).

Partindo de uma perspectiva expansionista, os escribas e cronistas do reino lusíada reproduziram um perfil oficial de Vasco da Gama, assegurando sua representação com base no valor da Areté, que é atribuída ao indivíduo que se destacou em coragem e honra no seio de seu A viagem continua grupo através de feitos extraordinários obtidos em situações de extrema dificuldade. Essas representações foram decisivas na modelação da mentalidade nacional portuguesa nos séculos subsequentes, contribuindo para a construção de um deslumbramento patriótico:

O orgulho do feito nacional, com a visão épica das navegações e das conquistas, predominou, durante gerações e gerações, sobre todos os outros sentimentos desencadeados pela Expansão na alma dos portugueses [...]. Ficou a constituir, desde o dealbar do século XVI, um ingrediente fundamental da maneira de nos concebermos na história ou de reagirmos perante a vida. [...]. Esta maneira de ver a nossa ação além dos mares penetrou profundamente nos espíritos. (DIAS, 1982, p. 15).

Em grande parte das manifestações culturais portuguesas, principalmente a partir da primeira metade do século XVI, se sobressai essa tendência para a exaltação mítica dos descobrimentos. A representação de Vasco da Gama entrelaça-se com o imaginário épico, do qual, primeiramente, as relações e as crônicas não conseguem se libertar. Não queremos dizer com isso que as reações pessimistas não se tivessem feito sentir, ainda que isoladamente, desde cedo. Os Lusíadas, de Luís de Camões, é, sem dúvida alguma, a obra mais conhecida que representa esse desencadear crítico.

Para os efeitos dessas reações na substância poética da obra de Camões, as ações representadas estão longe de ser somente protagonizadas por um jovem e esbelto personagem. Camões representa através 
da figura do Velho do Restelo os conselhos de alguém que já na velhice se cansou de sonhar com épocas de ouro. Seus conselhos sublimam o ideal patriótico e cristão exaltado na cronística anterior, encenando, em decadente teor cavalheiresco, o desprezo da vida:

Já que nesta gostosa vaidade

Daniel

Vecchio

Gerson

Luiz Roani

Tanto enlevas a leve fantasia,

Já que à bruta crueza e feridade

Puseste nome esforço e valentia,

[...]. (CAMÕES, 2002, p. 140).

Com a fala sapiente do Velho do Restelo, compreendemos que a épica de Camões não é simplesmente um poema de louvor e exaltação dos feitos nacionais. Essa é uma característica original da obra camoniana, na qual a repreensão substitui o louvor. É uma reflexão séria sobre a história e a sociedade portuguesa que revela grande preocupação por parte do poeta com as fragilidades provenientes da ideia de império. Essa realidade antitética da épica camoniana valoriza a experiência, ou seja, a vivência dos personagens que ultrapassa o horizonte celebrativo e maravilhoso geralmente registrado nesse episódio histórico.

A experiência de soldado de Camões parece tê-lo estimulado a não se deixar tomar por completo pelos domínios celebrativos realçados com muita fantasia. Assim o fez Camões, explorando diversos aspectos da realidade empírica, sejam eles da geografia, da astronomia, das ciências da natureza e da etnografia, enfim, informações que foram colhidas com o mais vivo interesse do poeta durante sua estadia no Oriente ${ }^{3}$.É nesse sentido empírico que a figura de Vasco da Gama parece estar centralizada em sua épica, e assim podemos perceber na cena em que é dada a resposta do Capitão ao rei Dom Manuel, depois de ter sido escolhido para comandar a armada de 1497:

[Dom Manuel] 'Eu vos tenho todos escolhido

Para uma empresa, qual a vós se deve,

3 “[...] segundo o cronista Pedro de Mariz, Camões foi enviado às partes da China, tendo estado em Macau e tendo sido vítima de um naufrágio, provavelmente na foz do rio Mecom, no Camboja, facto a que alude na estância 128 do Canto X dos Lusíadas, evocando a célebre salvação a nado com o manuscrito da sua obra na mão: <<Este [Mecom] receberá plácido e brando,/No seu regaço os Cantos que molhados/Vêm do naufrágio triste e miserando,/Dos procelosos Eixos escapados,/Das fomes, dos perigos grandes, quando/Será o injusto mando executado/Naquele cuja lira sonorosa/Será mais afamada que ditosa>>." (MACHADO, 1983, p. 46-47). 
Trabalho ilustre, duro e esclarecido,

[...].

[Vasco da Gama] Ó Rei subido,

Aventurar-me a ferro, a fogo, a neve

É tão pouco por vós, que mais me pena

Ser esta vida cousa tão pequena.

Imaginai tamanhas aventuras

Quais Euristeu a Alcides inventava:

A viagem

O leão cleoneu, harpias duras.

continua

O porco de Erimanto, a hidra brava,

Descer enfim às sombras vãs e escuras

Onde os campos de Dite a Estige lava;

Porque o maior perigo, a maior afronta,

Por vós, ó Rei, o espírito e carne é pronta'.

(CAMÕES, 2002, p. 135).

O que temos nesse excerto é a representação de um Vasco da Gama prudente e convicto da realidade oriental em que vai adentrar, a qual aparece isenta de seres divinos e criaturas espantosas. Trata-se, acima de tudo, de um personagem não menos exigido pela lição empírica que a poética de Os Lusíadas tem por essência. Contudo, tal tratamento da poesia não sustentará a sua evocação posterior. Seus versos serão substituídos, pela comunidade de leitores, por uma configuração simploriamente elogiosa, maravilhosa e nada antitética em relação ao episódio histórico representado.

O motivo dessa distorção na leitura dos versos camonianos pode ser explicado a partir de dois pontos. Primeiro, há de convirmos que, mesmo com essas características antitéticas, Os Lusíadas manteve-se predominantemente como um discurso imperialista que advoga para os portugueses a superioridade sobre outros povos. Para isso, basta observarmos o extenso espaço que ocupa a fala de Vasco da Gama nessa obra, ao discorrer grandiloquentemente sobre a genealogia dos reis portugueses ao governador de Melinde.

O segundo e último ponto é que, através de todas as vicissitudes da sociedade portuguesa, Camões e obra mantiveram-se como símbolo de uma nacionalidade evocada em momentos de crise nacional e 
de ameaça à integridade do império. Nesse sentido, Camões passa a ser visto, portanto, como o poeta do espírito do Renascimento, representante das forças progressivas e símbolo de uma nova civilização. Essa sublimada evocação épica de Camões se impôs em todos os ciclos comemorativos dos descobrimentos nos quais seu nome e sua poesia foram lembrados.

Daniel A fama de herói nacional do Gama continuou a exercer o seu fasVecchio cínio durante séculos. Apesar de os centenários comemorativos envolvendo personagens e acontecimentos da expansão marítima terem sido Gerson raros em Portugal durante muito tempo, esse silêncio terminara diante Luiz Roani das difíceis circunstâncias pelas quais passaram os portugueses durante todo o século XIX. O fracasso político e a consequente transferência da corte para o Brasil são mudanças que viriam representar um profundo golpe na imagem de grandiosidade que ainda se tentava manter de Portugal.

Ainda no final desse século, com a monarquia esfacelada, Portugal sofreu intensa pressão da política expansionista das potências europeias da época, que continuavam a ameaçar os interesses portugueses na África e na Ásia. Diante dessa pressão política, acentua-se uma profunda reação nacionalista, com base em uma larga produção de memória histórica com o intuito de realçar a capacidade de colonização e aptidão para a conquista territorial dos portugueses. "Memória decerto ineficaz em termos práticos, de política externa, nessa conjuntura que conduzira ao Ultimatum britânico de 11 de janeiro de 1890, cinco anos depois das exigências da Conferência de Berlim." (MATOS, 1998, p. 124).

Sérgio Campos Matos menciona a expressão "memória ineficaz" no sentido de que Portugal, nessa época, mais se preocupava em produzir uma memória aparente do que organizar o governo da casa de fato. A proliferação de um discurso comemorativo, reforçado amplamente por esculturas, pinturas, estudos históricos e produções literárias, contribuiu significativamente para a modelação de tal identidade portuguesa.

Esse impulso comemorativo teve como principal finalidade fazer com que os portugueses, vistos como entidade coletiva, se sentissem portadores das mesmas virtudes que caracterizavam os heróis da sua considerada idade de ouro. Isso servia também para mostrar que o povo português tinha condições para impor o respeito e a admiração das 
outras nações, voltando-se para a exploração dos territórios africanos como grande aposta de reabilitação nacional. ${ }^{4}$

Tal imposição de respeito e reconhecimento levantou longos e intensos debates entre diversos intelectuais, pois cada um justificava a sua respectiva nação a importância sobre a fundação da modernidade através da histórica expansão marítima europeia. As famosas depreciações contra os portugueses levantadas pelo naturalista e historiador alemão das ciências geográficas Alexandre Humboldt (1769-1859), por exemplo, suscitaram no país o desencadeamento de uma grande produção literária e historiográfica sobre o tema. ${ }^{5}$

Em resposta aos estudos do investigador alemão, o historiador português Visconde de Santarém (1791-1856) iniciou em Portugal essa tarefa de resgate das glórias nacionais, buscando provar a primazia porA viagem continua tuguesa na expansão marítima europeia: "Julgamos cumprir um dever para como nosso paiz em não guardar silencio em assumptos tão graves, no qual interessa não só a antiga gloria nacional, mas também a historia da geografia." (SANTARÉM, 1841, p. VII-VIII).

Trata-se de um período de larga exaltação épica sobre os navegadores que fizeram parte da fundação e do estabelecimento do império marítimo português, principalmente acerca do navegador Vasco da Gama, cuja viagem pioneira de 1497 estabeleceu um marco decisivo para o sucesso da expansão marítima europeia como um todo:

[...] tratarão de diminuir igualmente a gloria do grande feito de Gama. Descobrirão a passagem de Heródoto, tantas vezes citada, sobre a circunavegação d'Africa por uma expedição feita no tempo de Necos, a fim de mostrarem que o valeroso almirante tinha apenas achado o que já era conhecido na antiguidade [...]. (SANTARÉM, 1841, p. III-IV).

Em contrapartida, com os fundadores do Romantismo português, Almeida Garrett (1799-1854) e Alexandre Herculano (1810-1877), a

4 As celebrações dos centenários de Camões (1880), do Infante D. Henrique (1894) e do descobrimento do caminho marítimo para a Índia (1897-1898) foram os principais eventos que marcaram uma vasta produção de memória comemorativa que intensificou esse imaginário nacional.

5 Nos finais do século XIX, as teses de Humboldt foram invocadas para fundamentar e legitimar historicamente a política colonial do imperialismo alemão, reforçada na Conferência de Berlim. 0 cientista procurou tenazmente demonstrar, por um lado, a ignorância dos marinheiros portugueses e, por outro, a origem alemã da ciência náutica dos descobrimentos marítimos: "Todo estaba preparado para llegar al descubrimiento de la América tropical [...].” (HUMBOLDT, 1874, p. 255). 
cultura portuguesa começou a ser pensada de acordo com as necessidades e urgências socioculturais mais profundas do país, forma pela qual nunca fora pensada antes, reavaliando valores e repensando o imaginário épico cultural que tanto abalava a mentalidade da população lusa.

Com Alexandre Herculano, observamos uma inteligente inversão nos mecanismos de representação do cenário celebrativo e maravilhoso Daniel da história nacional portuguesa, abordando o enaltecimento épico da Vecchio tradição como uma miragem problemática para o presente e o futuro de seu povo. No primoroso conto intitulado "Três meses em Calecute" Gerson (1851), que foi lançado no segundo tomo das Lendas e narrativas, investe Luiz Roani o escritor no recontar da primeira viagem gâmica, e o modo como a viagem é traçada varia de acordo com a versão contada pelos tripulantes que participam ativamente de todo o conto, com destaques para a participação do intérprete de língua árabe, Fernão Martins, e do tripulante Álvaro Velho.

Enquanto Fernão Martins mostra-se como detentor de uma visão empírica dos acontecimentos, Álvaro Velho é pintado por Alexandre Herculano através da figura de um velho cuja visão está completamente enraizada em imaginários de toda espécie, aproveitando, desse modo, o historiador todo o seu conhecimento sobre a cultura medieval para tal caracterização:

[...] era essa nevoa incerta a nossa esperança, mas esta se desvanecia quando nos lembrávamos que havia três dias que, de hora a hora, de instante a instante, ilusões semelhantes vinham afigurar-nos próximas essas praias, aonde iam bater todos os nossos desejos, constância e trabalhos; essas praias da Índia, cujo nome era para nós como um primeiro amor, como um sonho formoso de madrugada, como um eflúvio do paraíso; rico de futuras grandezas, para nós e para o velho Portugal. (HERCULANO, 1984, p. 250-251).

Não encontraremos no século XIX uma descrição da viagem gâmica tão embasada pedagogicamente nos imaginários da tripulação como nesse conto. Temos aqui uma narrativa que retoma a memória fantasiosa do personagem que escrevera a única relação histórica conhecida da primeira viagem portuguesa às Índias. Lembremos que, como no conto, a relação de Álvaro Velho não deixa de ser uma narração marcada pela busca das próprias angústias mentais de seu relator, principalmente no 
que diz respeito à imaginária possibilidade de encontrar reinos cristãos no Oriente.

Contudo, grande parte da produção posterior não seguiu o ritmo de leitura e reflexão desse célebre escritor, com exceção, obviamente, dos intelectuais da Geração de 70. Era evidente que interessava à política incentivar mais a retomada de um passado mitificado e de uma tradição reinterpretada de acordo com valores virtuosos, do que uma demonstração das fraquezas mentais que poderiam naturalmente constituir a tripulação daquela simbólica viagem fundadora.

$\mathrm{Na}$ contramão desse viés celebrativo, atribui-se, principalmente a Antero de Quental, Oliveira Martins e Eça de Queiroz, a efetivação da A viagem continua revolução mental e ideológica iniciada por Herculano e Garrett. O que a caracterizou e a definiu verdadeiramente foi justamente essa

\footnotetext{
capacidade de mitificar a realidade, qualquer que fosse, impondo-lhe um estilo, atribuindo-lhe um papel no vasto drama espiritual em que se convertera para eles a Cultura e de que eles mesmos eram ao mesmo tempo os atores, os inventores e os consumidores consumidos. (LOURENÇO, 1999, p. 123).
}

A Geração de 70 se distanciará das grandes comemorações governamentais de 1880 em diante, sublinhando sempre o contraste entre o estado real do país e a grande máscara de que Camões era alvo, principalmente a partir da comemoração do terceiro centenário de sua morte:

\footnotetext{
Foi por esse Portugal encarnado por Gonçalo Mendes Ramires, tão outro do que suscitara nos anos 60 e 70 a urgência de um eletrochoque, que a Geração de 70 foi acusada até de perjúrio aos seus ideais revolucionários, terminando melancolicamente por converter o seu propósito crítico e construtivo da juventude em discurso mítico, simbólico e messiânico. (LOURENÇO, 1999, p. 121).
}

Lutava-se pelo objetivo comum de fazer acordar o país através de um tratamento de choque evidenciando "as vísceras cancerosas das suas elites, [...] mostrando a fortíssima carga de preconceitos morais e imaginários sem fundamento que envolve os comportamentos e tradições populares" (REAL, 2001, p. 30). O legado crítico da Geração de 70 
não resistiu, infelizmente, às políticas conservadoras que se mantiveram em Portugal durante quase todo o século XX, sofrendo um prolongado estado de silêncio e fazendo com que fosse cada vez menos difundido esse misticismo irônico constituído por tipos e formas literárias de irracionalidade imaginária.

Por outro lado, a Sociedade de Geografia de Lisboa, ativa desde Daniel 1875, reunia um grupo específico de intelectuais liberais que se mosVecchio travam mais preocupados e empenhados em contribuir para o avanço das investigações em função unicamente de fundamentar as posições Gerson gloriosas de Portugal nas batalhas diplomáticas internacionais que surLuiz Roani giam em torno das questões coloniais. Contudo, essa memória histórica liberal também permitiu e conservou aspectos menos abonatórios da 188 imagem idealizada de seus heróis nacionais. Claro que isso ocorrera de forma bem menos intensa do que se deu com alguns românticos e com os intelectuais da Geração de 70, e para tal demonstração tomamos o exemplo de José de Sousa Monteiro (1846-1909), que realizou um curioso estudo histórico sobre a conturbada psicologia de Vasco da Gama.

Esse investigador considera a construção da personalidade de Vasco da Gama partindo de hipotéticas marcas traumáticas no decorrer de sua vida. $O$ estudioso afirma que fatos ainda por nós desconhecidos poderiam ter feito com que o Capitão guardasse durante toda a vida uma espécie de ferida, de "silêncio pertinaz" (MONTEIRO, 1898, p. 498). Diante desse trauma, Vasco da Gama teria crescido de forma tão impetuosa que, ao dominar uma ideia, a absorvia em grande tensão: “[...] nada vê, nada sente, nada quer, além dessa ideia, dessa tenção [...]" (MONTEIRO, 1898, p. 503).

Essa versão corrobora a defesa de que o Gama teria naturalmente tentado a todo custo reparar os danos causados à sua família, que de alguma forma ficou sem os bens pertencentes ao seu pai, Estevão da Gama (1430-1497?), possivelmente assassinado, danos causados principalmente pela perda do governo de Sines. A coragem de enfrentar a perigosa empresa marítima de 1497, empresa essa que realizou por três vezes, não nos deixa mentir sobre essa euforia. Fixada a ideia de ascensão, tomar a frente de qualquer empresa misteriosa e grandiosa poderia ser a única chance de Vasco marcar novamente o nome dos Gama nas gestas de sua nação.

Porém, Sousa Monteiro revela que o Almirante 
regressara sem devassar o singular mysterio, abrindo apenas com a proa da sua caravella um rasgão no véu de sombras imperscrutáveis na apparencia que velava a toda cobiça a India de luz e de ouro. Pois teve Vasco da Gama essa séria, forte, inflexível firmeza. Encheu-se della, converteu-se nella. Luctou com pavores reaes e com sonhados pavores, que não são menos terríveis que os reaes, com a perfídia do mar e do tempo e com a perfídia dos homens [...]. (MONTEIRO, 1898, p. 499-500).

O perfil psicológico do navegador é tomado por essa fixidez irresoluta de desejos e traumas. Seguindo a perspectiva crítica de um Alexandre Herculano e outros intelectuais mais críticos, Sousa Monteiro A viagem continua revela, sobretudo, a problemática mentalidade maravilhosa de Vasco da Gama, outorgando-lhe o papel negativo de reproduzir descontroladamente "sonhados pavores" que faziam parte de seu imaginário.

Mais adiante, diferentemente da incipiente República das primeiras décadas do século XX, as comemorações dos descobrimentos marcaram um ponto alto na história das realizações do regime ditatorial que vigorou entre o golpe militar de 1926 e o estabelecimento do Estado Novo em 1933-1934. A conduta da trajetória política, que haveria de desembocar em um regime profundamente conservador, ficou a cargo de Antonio de Oliveira Salazar, o ministro das Finanças nomeado em 1928: "O salazarismo utilizou como instrumentos de manutenção do poder o controle policial e administrativo sobre as liberdades de expressão e de associação e o controle social sobre as classes subalternas através de um corporativismo parcial e misto." (JOÃO, 2002, p. 91).

Desse modo, não foi dada a continuidade para as pesquisas em avanço de um Alexandre Herculano ou José de Sousa Monteiro quanto aos aspectos enigmáticos da biografia de Vasco da Gama. Durante o regime, os aspectos negativos de sua biografia e a de qualquer outra figura de expressão da nacionalidade lusitana foram considerados uma afronta à conservação do poder e da tradição. Ademais, nos Anos 30, o salazarismo desenvolveu uma grande campanha de propaganda celebrativa em torno do império.

Esse domínio pode ser observado através da vasta produção de estudos técnicos sobre a ciência náutica ${ }^{6}$ portuguesa que preenchiam

6 "Nessa perspectiva, destacamos os estudos de Joaquim Bensaúde, que desfez as lendas alemãs 
todos os eventos comemorativos. Com a proliferação desse campo, era a historiografia moderna que se rejeitava na íntegra, com suas bases na sociologia e na economia, sob o pretexto salazarista de evitar a infiltração de um materialismo histórico comunista. ${ }^{7}$ Apesar disso, a historiografia portuguesa tinha conhecido um desenvolvimento significativo nesses aspectos mais humanísticos durante tal período, surgindo muitas obras Daniel críticas de referência da história nacional, como os estudos de Jaime CorVecchio

Gerson tesão, Vitorino Magalhães Godinho, Hernani Cidade, entre outros.

No entanto, a reviravolta historiográfica dos descobrimentos Luiz Roani estava nesse momento mais propícia a ser executada no e pelo estrangeiro, devido a esse intenso policiamento salazarista. É a partir dessa conjuntura sociopolítica que se destacam alguns estudos de pensadores indianos, como o estudo de Kavalam Madhava Panikkar (1895-1963), com a obra intitulada Asia and Western dominance, cuja primeira edição surgiu em 1953 com o subtítulo A survey of the Vasco da Gama epoch of Asian history $1498-1945 .^{8}$ O perfil do Almirante que emerge em suas análises dificilmente se enquadra na visão que se poderia fazer de um herói civilizador, sendo constituído na "medida do terrorismo e da pirataria que ele inaugurou nos mares indianos [...]." (PANIKKAR, 1965, p. 50).

Em território português, precisamos esperar a renovação cultural e uma consequente abertura democrática ancorada nos valores engendrados pela Revolução dos Cravos para começar a trilhar as demolições efetivas dos mitos erigidos pela memória épica portuguesa produzida até o fim do regime salazarista. Vasco da Gama, igualmente, não escapou dessa revisão literária e historiográfica. No caso da produção histórica, a revisão demorou a ocorrer e somente a partir da aproximação do ano de 1998 é que surgiu uma nova vaga de estudos e ensaios críticos sobre o navegador em função das comemorações do $5^{\circ}$ centenário da primeira viagem à Índia. ${ }^{9}$

quanto às origens da náutica astronômica alemã; os estudos de Fontoura da Costa na obra A Marinharia dos Descobrimentos (1934) e temos, também, as inúmeras contribuições de Gago Coutinho em A Náutica dos Descobrimentos (1951-1952)." (GODINHO, 2008, p. 29).

7 Tais ideias eram manifestadas através das comemorações, como a organização da I Exposição Colonial Portuguesa de 1934, O Duplo Centenário de 1940 e as Comemorações Henriquinas de 1960, que formam o conjunto das iniciativas desenvolvidas com vistas a forjar uma consciência nacional da importância histórica e do valor político-econômico imperialista.

8 Tradução do autor: "A Dominação Ocidental na Ásia”/“A Sobrevivência do Tempo de Vasco da Gama na História da Ásia”. Refere-se tal título à época de Vasco da Gama da história asiática (14981945), um período que pode ser definido como uma era de poder marítimo das nações europeias.

9 Nesse ciclo comemorativo, dos estudos mais significativos, devemos destacar os estudos feitos por Luís Adão da Fonseca e pelo historiador indiano Sanjay Subrahmanyam, intitulado The carrer and 
No caso da produção literária portuguesa contemporânea sobre o tema das viagens gâmicas, podemos apontar que as vozes de historiadores orientais como Panikkare Subrahmanyam representam o ponto de vista do outro que impulsionou e facilitou, histórica e antropologicamente, a formação de variáveis ideológicas e discursivas que são criticamente próximas dos romances contemporâneos produzidos em Portugal.

Nessa perspectiva, encontramos obras de Lidia Jorge e António Lobo Antunes, por exemplo. O último, na obra As naus de 1988, parodia o heroísmo coletivo lusitano ao invocar uma raça de heróis navegadores do ultramar que definham ao voltarem para Portugal muitos séculos depois:

Porra, consolou-se ele [Vasco da Gama] a viajar com ódio o recuo do Tejo: apesar de tudo nomearam-me conde. E lembrou-se de quando o chamaram ao Paço, lhe entregaram uma frota e o mandaram à Índia, oferecendo-lhe, para o ajudar, um maço de mapas de continentes inventados, pilhas de relatórios mentirosos de viajantes pedestres e um capuchinho de cilício e terço em punho, investido da tarefa específica de benzer os moribundos. (ANTUNES, 2000, p. 113).

Com uma ironia acentuada que surge de imediato em cada sentença da obra, Lobo Antunes traça um Vasco da Gama indignado com alguns detalhes, como o desimportante título de Conde da Vidigueira, a escassa premiação de D. Manuel com medalhas, diplomas e passeios no seu carro aos domingos e o próprio feito marítimo de 1497, episódio esse sobrecarregado na obra de "mapas e continentes inventados". Com efeito, As naus desconstrói a dimensão épica da gesta ultramarina através de uma representação antitética do discurso oficial no plano ideológico e da forma clássica no plano estético.

Mas, em complementação a esse dialogismo que contrapõe a história oficial no texto literário a todo instante, é preciso ressaltar, sobretudo, que no viés crítico dessa literatura há também muitas obras, como as de Urbano Tavares Rodrigues (Do tamanho do mundo) e José Saramago (A ilha desconhecida), que substituíram a mitologia cultural imposta pelo

legend of Vasco da Gama (1997). Tais investigações se destacam por empreender um levantamento historiográfico do Gama mediante a exploração do potencial de lenda celebrativa que o seu feito inevitavelmente contém. 
regime por uma espécie de imaginário fabuloso alegórico, que nada mais é do que "a imagem e o contradiscurso de um povo que tinha perdido a sua independência política, a sua identidade [...]" (LOURENÇO, 1999, p. 48).

Ao se libertar do monologismo representativo de uma dada cultura ou de um dado discurso, o romance português tem ressonâncias Daniel muito amplas, que vão além de somente apresentar uma versão paróVecchio dica acabada do discurso oficial, sendo livre para investigar o fenômeno da alienação e da opressão em diferentes circunstâncias e formas. Gerson Entretanto, por razões diversas, a alegoria, bem como outras formas Luiz Roani anteriores de representação, não tem sido muito apreciada pela crítica literária contemporânea:

\begin{abstract}
A alegoria é, e curiosamente, mais que qualquer outra forma literária, uma constante da produção literária ocidental. Se, com raras exceções, escritores e críticos atuais não nomeiam o conceito, isso não impede que a especificidade de uma boa parte da literatura contemporânea possa (deva) ser compreendida em função dele. [...] a dinâmica estrutural da realização alegórica assenta em vertentes cuja identificação é fulcral para se entender o quadro das exigências teóricas e culturais do nosso tempo. (MARTINS, 1984, p. 7).
\end{abstract}

Em contrapartida ao reconhecimento dessa linha expressiva da literatura atual, convivemos com uma tendenciosa crítica literária focada nos fatores pós-modernos, que "se reduz, quase sempre, pela forma negativa do texto, a partir de um feixe de traços filosóficos ou estilísticos opostos ao discurso oficial" (PERRONE-MOISÉS, 1998, p.183). Mas reforçamos a afirmativa de que a narrativa literária contemporânea manifesta-se não somente a partir da constante representação distorcida da forma e da ideologia de um código opressor, mas também a partir do esgotamento da sua univocidade, legitimando as ações humanas sob um significado alegórico da tradição que persiste até sucumbir em um desfecho.

Vimos anteriormente que foi com Herculano, Garret e a Geração de 70 que se difundiu, de fato, a leitura crítica de um Portugal doente, de vida coletiva embebida no imaginário épico que embaçava a decadência nacional em que viviam. Apesar da aproximação dessas gerações no que 
tange à crítica cultural, é preciso termos em mente que, na atual literatura, a modelação alegórica específica desse código opressor consiste em uma reposição formalmente mais complexa dos cenários da história, marcada por um acentuado fluxo de consciência de seus anti-heróis.

No entanto, o que nos importa salientar no momento é que os mesmos problemáticos fatores culturais de outrora são relevados por pensadores como Eduardo Lourenço e Miguel Real, que os enxergam ainda persistentes nas décadas posteriores à Revolução dos Cravos, com um país imerso em intensa crise política, econômica e, sobretudo, cultural.

Há um irrealismo cultural existente entre o discurso oficial do A viagem continua

Estado, dominante na imprensa escrita, e o próprio progresso normal de Portugal, atualizando-se tecnologicamente, mas permanecendo em seu fantástico e insatisfeito irrealismo social, uma convicção subterrânea e já triunfante de que não vamos e não estamos indo para lado algum que mereça o fervor e a pena da caminhada, um presente subitamente pleno de aventuras oníricas em que sobra a ausência de uma aventura anímica comum. (REAL, 2012, p. 91-92).

A representação literária desse "irrealismo cultural" em algumas obras literárias resulta em uma provocante alegoria de efeito irônico, impregnada de misticismo e religiosidade para narrar e descrever o país. Observamos que, diante de uma discussão cultural de tão longa data, torna-se evidente haver o imaginário exercido grande influência sobre a formação cultural portuguesa. Nesse viés, devemos destacar um dos romances contemporâneos mais elaborados nessa estética que cobre as representações de Vasco da Gama e sua viagem pioneira: a Peregrinação de Barnabé das Índias (1998), do portuense Mário Cláudio. Tal obra está

\footnotetext{
diretamente ligada ao tema da opressão proveniente do peso da tradição, que não só condena Portugal à retrógrada valoração de conquistas do passado, mas também leva o país a um solipsismo doentio e mesmo ao culto de um misticismo guerreiro de consequências desastrosas [...]. (GOMES, 1993, p. 85).
}

Na Peregrinação de Barnabé das Índias, cuja viagem de descobrimento de 1497 é o seu núcleo gerador, o imaginário opressor constituído 
de lendas foi uma forma instigante e produtiva que o autor encontrou para explorar a identidade portuguesa em estado de crise, pois é isso que parecia dominar Portugal nos últimos anos do século XX, momento inundado pela vaga cultural de muitas formas de irrealismo pelas quais o autor escreveu seu romance. É através dessa linha que Mário Cláudio revê a época das navegações portuguesas, explorando uma imaginária

Daniel versão para a viagem inaugural do caminho marítimo para as Índias:

Vecchio

Gerson

Luiz Roani

E percorrendo estes devaneios dilatados minutos, neles compreendi que não equivalia a avistada de bordo à minha povoação de fantasia, porque a que lhe ia botando eu [Vasco da Gama] em cima em nada se comparava à que realmente existia, em conseqüência de jamais vislumbrarmos no que se nos depara a completa verdade para que propendemos, seja ela agradável ou nefasta, mas uma envergadura onde os sonhos se cruzam com os desejos, e os torpores se misturam com os júbilos, e tão vulgar se faz este jogo que nele nem atentam os que o executam, e cada região achada em região dissipada se converte, e cada viagem em nova decepção, e se considerarmos que para o lado de lá se nos não antolha esplendor ou triunfo, antes morte da visão que da autêntica Cidade se separou, deduziremos que não significará a imaginada senão um engano do olhar. (CLÁUDIO, 1998, p. 208-209).

Os desvios oníricos da viagem, que refletem o mais puro sofrimento desses peregrinos, são causados pelo fato de não haver na história o estabelecimento coletivo de uma tomada de consciência relativa ao olhar que direcionam os tripulantes ao mundo oriental. 0 recorrente verbo "antolhar" no romance serve para transfigurar a ação dos tripulantes mediante um limite cognitivo imposto pela tradição imaginária a respeito das terras e dos povos do Oriente. No trecho citado, retirado do capítulo "As cidades", apresenta-se Vasco da Gama desiludido e ao mesmo tempo encantado na sua primeira mirada a Calicute, cidade rica em especiarias de todo trato, que tanto desejavam descobrir os portugueses. Considerando tais prerrogativas, aponta Miguel Real que, ao

estabelecermos um arco temporal de cem anos e relendo alguns dos mais importantes romances portugueses das últimas décadas dos séculos XIX e XX, ressalta espontaneamente a conclusão de que o seu conteúdo reflete comumente uma sociedade 
bloqueada, que vive quase exclusivamente de preconceitos e ilusões sociais [...]. (REAL , 2001, p. 19).

Nessa perspectiva, por fim, analisamos por diferentes meios e épocas a possibilidade deabordar a história ultramarina portuguesa partindo criticamente da reprodução do discurso que a história oficial estimulou largamente através dos elementos maravilhosos e celebrativos da épica tradicional, revelando uma imagem que tem menos a ver com Portugal e o Oriente do que com o mundo idealizado pelos próprios portugueses.

\section{Referências}

ANTUNES, António Lobo. As naus. 4. ed. Lisboa: Publicações Dom Quixote, 2000.

BARRETO, Luís Filipe. Descobrimentos e Renascimento: formas de ser e pensar nos séculos XV e XVI. 2. ed. Lisboa: INCM, 1983.

CAMÕES, Luís de. Os Lusíadas. Notas de Hernâni Cidade. São Paulo: Nova Cultural, 2002.

CANDAU, Joel. Memória e identidade. Trad. de Maria Leticia Ferreira. São Paulo: Contexto, 2012.

CLÁUDIO, Mário. Peregrinação de Barnabé das Índias: romance. 2. ed. Lisboa: Publicações Dom Quixote, 1998.

DIAS, José Sebastião da Silva. Os descobrimentos e a problemática cultural do século XVI. Lisboa: Editorial Presença, 1982.

DISNEY, Anthony. A expansão portuguesa (1400-1800): contatos, negociações, interações. In: CURTO, Diogo Ramada; BETHENCOURT, Francisco. A expansão marítima portuguesa (1400-1800). Trad. de Miguel Mata. Lisboa: Edições 70, 2010. p. 295-326. 
FONSECA, Luís Adão da. Vasco da Gama, o homem, a viagem, a época. Lisboa: Parque Expo' 98, 1997.

GODINHO, Vitorino Magalhães. A expansão quatrocentista portuguesa. 2. ed. Lisboa: Dom Quixote, 2008.

Daniel GOMES, Álvaro Cardoso. A voz itinerante: ensaio sobre o romance Vecchio português contemporâneo. São Paulo: Ed. da USP, 1993.

Gerson HALBWACHS, Maurice. A memória coletiva. Trad. de Beatriz Sidou. Luiz Roani Lisboa: Centauro, 2006.

196 HERCULANO, Alexandre. Três meses em Calecute. In: Lendas e narrativas. Lisboa: Livraria Bertrand, 1984 (1851). Tomo II. p. 230-258.

HUMBOLDT, Alexandre. Desarrollo de la Idea del cosmos. In:

Cosmos. Ensayo de uma descripcion física del mundo. Vertido al castellano por Bernardo Giner y Jose de Fuentes. Madrid: Imprenta de Gaspar Y Roig Editores, 1874. Tomo II. p. 199-226.

JOÃO, Maria Isabel. Memória e império: comemorações em Portugal (1880-1960). Lisboa: Fundação Calouste Gulbenkian e Fundação para a Ciência e a Tecnologia, 2002.

LOURENÇO, Eduardo. Mitologia da saudade: seguido de Portugal como destino: dramaturgia cultural portuguesa. São Paulo: Companhia das Letras, 1999.

MACHADO, Álvaro Manuel. 0 mito do Oriente na literatura portuguesa. Lisboa: Biblioteca Breve, 1983. v. 72.

MARTINS, Manuel Frias. Para uma compreensão e fundamentação teórica do conceito de alegoria literária. Revista Colóquio/Letras, Ensaio, n. 79, p. 7 -15, maio 1984.

MATOS, Sérgio Campos. O centenário da Índia no Portugal finissecular. In: HESPANHA, António Manuel (Org.). $0 \ll$ Centenário 
da Índia>> e a memória da viagem de Vasco da Gama. Lisboa: Comissão Nacional para as Comemorações dos Descobrimentos Portugueses, 1998. p. 119-139.

MONTEIRO, José Sousa Monteiro. Vasco da Gama (A psychologia d'um heroe). Revista Portugueza Colonial e Maritima, Lisboa: Livraria Ferin, v. 2, p. 495-506, 1898.

OSÓRIO, Jerônimo. Da vida e feitos d'el Rei D. Manoel. Lisboa: Impressão Regia, 1804. Tomo I.

PANIKKAR, K. M. A dominação ocidental na Ásia: do século XV aos nossos dias. Trad. de Nemésio Salles. Rio de Janeiro: Saga, 1965. 2 v.

PERRONE-MOISÉS, Leyla. Altas literaturas: escolha e valor na obra crítica de escritores modernos. São Paulo: Companhia das Letras, 1998.

PINTO, João Rocha. A viagem, memória e espaço: a literatura portuguesa de viagens: os primitivos relatos de viagem ao Índico (14971550). Cadernos de História Económica e Social, Lisboa: Livraria Sá da Costa Editora, n. 11-12, 1989.

REAL, Miguel. Geração de 90: romance e sociedade no Portugal contemporâneo. Porto: Campo das Letras, 2001.

O romance português contemporâneo. Alfragide, Portugal:

Editorial Caminho, 2012.

SANTARÉM, Visconde de. Memória sobre a prioridade dos descobrimentos portugueses na costa d'África Occidental. Pariz: Livraria Portugueza de J. P. Aillaud, 1841.

VELHO, Álvaro. o descobrimento das Índias: o diário da primeira viagem de Vasco da Gama (1497). Trad. de Ângela Ritzel; Introdução, notas e comentários finais de Eduardo Bueno. Rio de Janeiro: Objetiva, 1998. 
